\title{
Notes on the vocalizations of Blue-headed Fantail (Rhipidura cyaniceps)
}

Peter Boesman

In the following we briefly analyze and compare voice of the different races of Blue-headed Fantail (Rhipidura cyaniceps). We also try to quantify the extent of any vocal differences using the criteria proposed by Tobias et al. (2010), as a support for taxonomic review.

We have made use of sound recordings available on-line from Xeno Canto (XC) and Macaulay Library (ML).

Available recordings from Luzon (races pinicola and cyaniceps) are vocally all about the same (see examples below): only known vocalization is a short brisk 'skit!', sometimes combined into short less emphatic rattles (it is unclear if this is actually the song).

pinicola

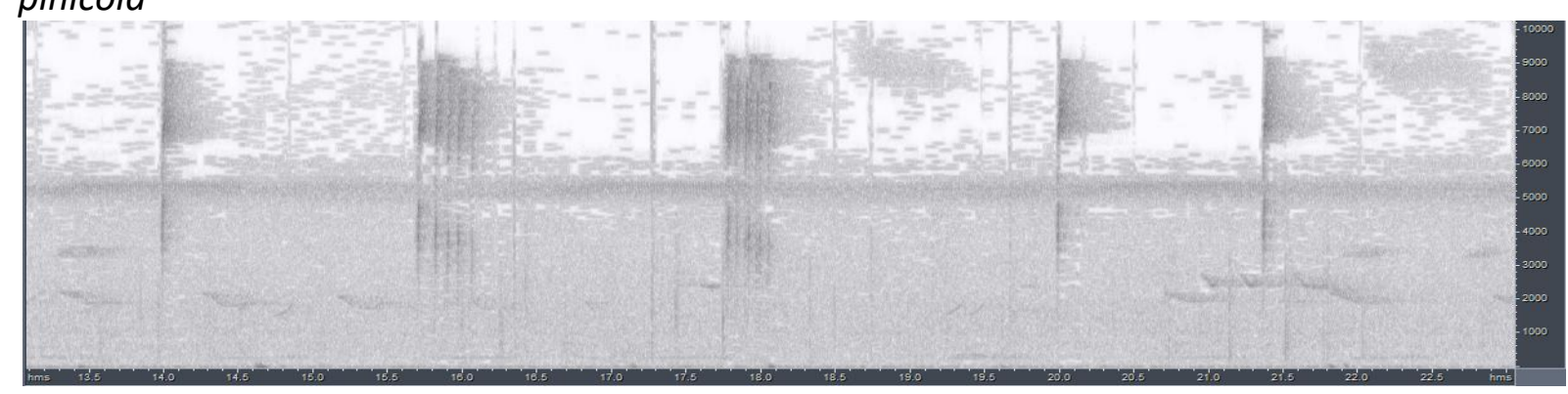

cyaniceps

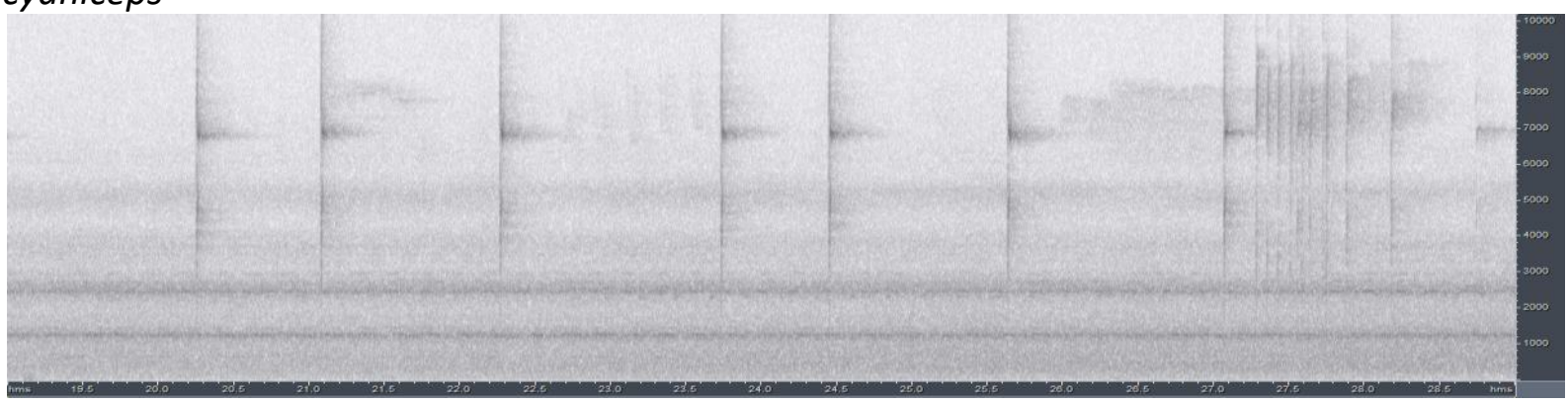

In albiventris, notes sound very different, more nasal. On a sonogram differences are very clear: notes are much lower-pitched and slightly longer in duration, show clear harmonics and have an overslurred shape.

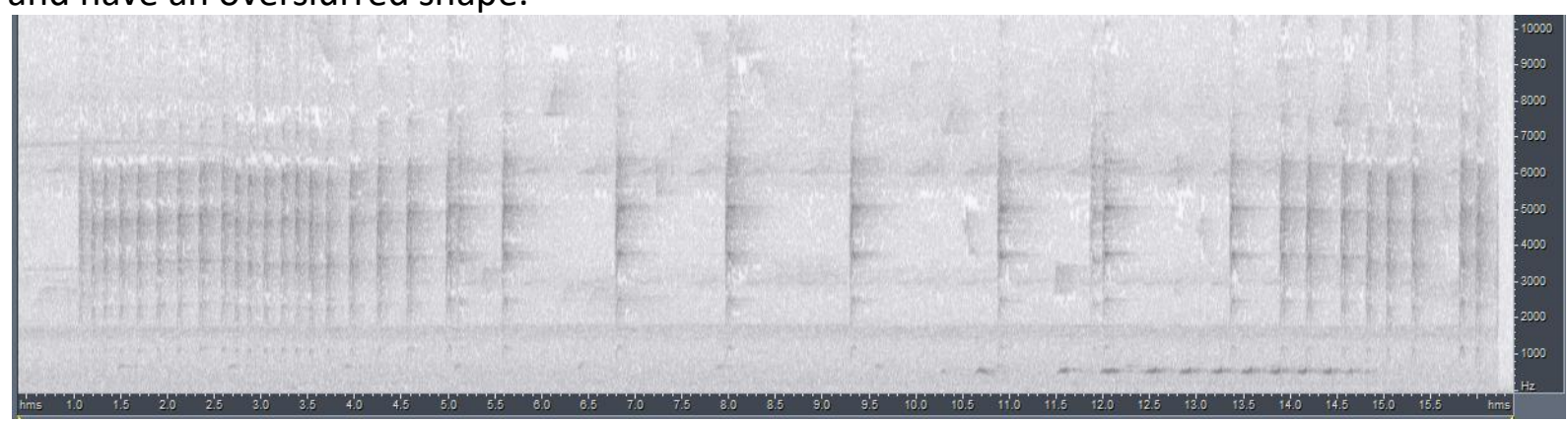



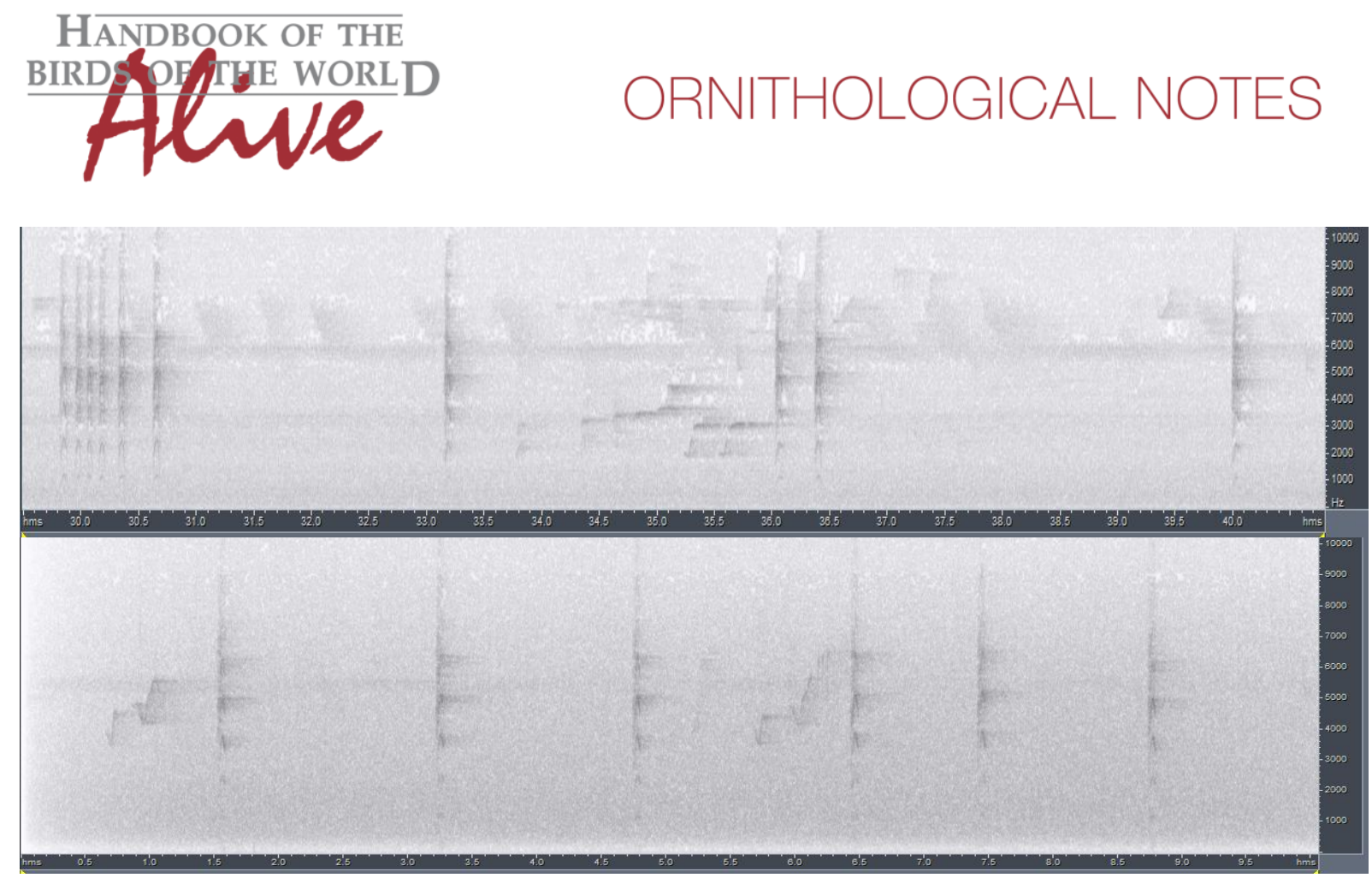

We have no recordings available of race sauli.

Assuming above vocalizations are homologous (song?), there is a structural similarity, but the notes in the song are very different:

pinicola/cyaniceps: note length $0.015-0.03$ s vs albiventris note length $0.05-0.07 \mathrm{~s}$ (score 3 ). pinicola/cyaniceps: max. freq. base harmonic $c 5000 \mathrm{~Hz}$ vs albiventris $c 1000 \mathrm{~Hz}$ (score 4). and note shape overslurred in albiventris. Application of Tobias criteria would lead to a total vocal score of 7.

This note was finalized on 12th January 2016, using sound recordings available on-line at that moment. We would like to thank in particular the sound recordists who placed their recordings for this species on XC and ML: Desmond Allen, David Edwards, Peter Hosner, Robert Kennedy, Frank Lambert, Ding Li Yong and George Wagner.

\section{References}

Tobias, J.A., Seddon, N., Spottiswoode, C.N., Pilgrim, J.D., Fishpool, L.D.C. \& Collar, N.J. (2010). Quantitative criteria for species delimitation. Ibis 152(4): 724-746.

\section{Recommended citation}

Boesman, P. (2016). Notes on the vocalizations of Blue-headed Fantail (Rhipidura cyaniceps). HBW Alive Ornithological Note 433. In: Handbook of the Birds of the World Alive. Lynx Edicions, Barcelona. (retrieved from http://www.hbw.com/node/1275617 on 8 December 2016). 
HANDBOOK OF THE

BIRDŚPF THE WORLD

ORNITHOLOGICAL NOTES

3 